\title{
HEC-RAS İle Taşkın Modelleme ve Sentinel-2 Uzaktan Algılama Görüntüsünden Taşkın Hasar Analizi: Diyarbakır İli Çakmak Deresi Çınar Bölgesi Örneği
}

\author{
Yunus Tektaş*1 ${ }^{*}$, Nizar Polat $^{2}$ (D) \\ ${ }^{1}$ Devlet Su Ișleri 10. Bölge Müdürlüğü, 101. Şube Müdürlüğü, Harita Mühendisi, Diyarbakır, Türkiye \\ ${ }^{2}$ Harran Üniversitesi, Mühendislik Fakültesi, Harita mühendisliği, Șanlıurfa, Türkiye
}

\author{
Anahtar Kelimeler: \\ HEC-RAS \\ Taşkın Analizi \\ QGIS \\ SCP \\ Uzaktan Algılama
}

\begin{abstract}
ÖZ
Taşkın, akarsu yatağında su iletim kapasitesinin çeşitli nedenlerle düşmesi veya akarsu yatağında iletileceğinden daha çok suyun olması halinde suyun yatak dışına taşarak can ve mal kaybına neden olabilen ve önlem alınması gereken önemli afetlerdendir. Artan nüfus yoğunluğuyla beraber çarpık kentleșmenin artmasıyla taşkınlar sonucu can ve mal kayıplarının da yaşanmasını kaçınılmaz kılmaktadır. Son yıllarda hayatın her alanına girmeye başlayan Coğrafi Bilgi Sistemleri ile taşkın risk analizlerine dayalı taşkın risk haritaları, yerleșim planlamalarında esas alınan öncelikli etmen olmaya bașlamıștır. $\mathrm{Bu}$ çalışmada Diyarbakır ili Çınar ilçe Merkezine ait 1/1000 ölçekli hâlihazır haritası ve dere yatağı üzerindeki menfezlerin röleveleri tedarik edilmiştir. Elde edilen hâlihazır harita ve röleveler HEC-RAS programında ișlenerek Çakmak Deresinde 1 boyut ve 2 boyut hidrolik hibrit model çalışılmıştır. Çakmak deresinin 2020 yılına ait Sentinel-2 uydu görüntüsü elde edilip uzaktan algılama ile QGIS SCP eklentisi kullanılarak Sentinel-2 görüntüsünün kontrollü sınıflandırması yapılıp yerleşim yerleri ve tarım arazileri belirlenmiştir. Hidrolik model sonucu oluşan taşkın yayılımı ile uzaktan algılama ile üretilen arazi kullanım durumu çakıştııılıp, taşkından etkilenen yerleşim alanlarının ve tarım arazilerinin yüz ölçümleri belirlenmiștir.
\end{abstract}

\section{Flood Modeling with HEC-RAS and Flood Damage Analysis from Sentinel-2 Remote Sensing Image: Example of Çakmak Creek (Çınar Region) in Diyarbakır}

\author{
Keywords: \\ HEC-RAS \\ Flood Analysis \\ QGIS \\ SCP \\ Remote Sensing
}

\begin{abstract}
Flood is one of the important disasters that may cause loss of life and property by spilling the water out of the river bed due to various reasons or if there is more water than the capacity in the streambed. With the increasing population density and the increase of unplanned settlements, the loss of life and property as a result of floods becomes inevitable. Especially with the Geographical Information Systems that have started to enter every field of life in recent years, risk maps based on flood risk analysis have become the primary factor in settlement planning. In this study, 1/1000 scaled map of Çınar district of Diyarbakır province and the reliefs of the culverts on the stream bed were provided. The obtained maps and relays were processed in the HEC-RAS program and a hydraulic model was studied by integrating 1 dimension and 2 dimensions in Çakmak Creek. Sentinel-2 satellite image of Çakmak stream for the year 2020 was obtained and controlled classification of Sentinel-2 image was made using remote sensing method and QGIS SCP plug-in, settlements and agricultural lands were determined. The flood propagation resulting from the hydraulic model and the land use situation produced by remote sensing technique are overlapped; Surface measurements of settlements and agricultural lands affected by floods were determined.
\end{abstract}




\section{GíRIş}

Taşkın; akarsu yatağında su iletim kapasitesinin çeşitli nedenlerle düşmesi veya akarsu yatağında iletileceğinden daha çok suyun olması durumunda, suyun yatak dışına taşması sonucu can ve mal kaybına neden olabilen ve önlem alınması gereken önemli afetlerdendir (Sargın, 2013). Taşkının doğal afet olduğu bilinse de insanların doğaya sürekli müdahaleleri sonucu; her geçen gün şiddeti ve sayısı yükselmektedir. Ülkemizde, bölgesel iklim şartları, topoğrafya ve yağış alanı gibi etkenler büyük taşkınların oluşmasına sebep olmaktadır. Doğal afetleri engellemek mümkün olmasa da zarar verici etkilerinin kontrol edilebilmesi ve önlenebilmesi için önlemler alınmalıdır. Taşkınların neden olduğu zararlar dünyada olduğu gibi ülkemizde de büyük önem taşıdığından, oluşabilecek ekonomik ve sosyal zararları minimuma indirmek büyük önem taşımaktadır. Yaşanmış taşkın envanterlerine, hazırlanmış taşkın hidrolik modellerine ve hidrometrik-meteorolojik gözlem verilerine dayanarak akarsuya belli mesafede yapılaşma yapılmaması taşkın riskini en aza indirecektir (Ercan vd., 2019).

Tașkınların meydana gelmesinde yer yüzeyinin pürüzlülügünün etkisi vardır. Yer yüzeyi üzerinde topografyadan sonra akışlar üzerinde en önemli değişken yüzey pürüzlülügüüdür. Pürüzlülük parametresindeki belirsizlikler su derinliğini belirlemede hatalara neden olmaktadır. Bu nedenle, hidrolik modellerde yer yüzeyinin su akışına karşı direncini tanımlayan Manning'in n veya Chezy'nin C gibi hidrolik sürtünme katsayılarının kullanılmasıyla pürüzlülüğün etkisini parametrelendirmek gerekmektedir. Uzaktan alglama ile yüksek çözünürlükteki uydu görüntülerinden arazi örtüsü/ kullanımı verileri elde edilebilmektedir. Elde edilen bu arazi örtüsü/kullanımı haritaları ile taşkın alanlarının sürtünme katsayıları daha doğru belirlenmekte olup daha gerçekçi hidrolik modellemeler kurulabilmektedir (Bolat, 2019).

Özcan (2008), Uzaktan algılama ile uydu görüntülerini kullanarak sınıflandırma yapıp arazi kullanım durumunu belirlemiş. Bu sınıflandırılmış uydu görüntüleri sürtünme katsayılarının belirlenmesinde ve taşkından etkilenen alanların belirlenmesinde kullanmış. HEC-RAS paket programını kullanarak Sakarya il sınırının bir kısmını da içeren Sakarya Nehri alt havzasının taşkın analizini yapmış: analiz sonucunda 620 ha yerleşim alanı ve 3330 ha tarım arazisinin taşkından etkilendiğini ortaya koymuş.

Efe (2014); HEC-RAS paket programını kullanarak Batman Çayı üzerinde bulunan BatmanMalabadi yolu köprüsü ile Batman-Diyarbakır yolu köprüsü arasındaki kısmının taşkın analizini yapmış, analiz sonucunda çalışma güzergâhında yer alan Şerbet ve Bıçakçı Köyleri'nin tarım arazilerinin taşkından etkileneceğini ortaya koymuş, DSİ tarafından geliştirilen Batman Çayı ıslah projesinin taşkın kontrol kesitini tahkik etmiş, projenin kesitinin yeterli olacağını ortaya koymuştur.

Akkaya (2016); HEC-RAS paket programını kullanarak Meriç ve Tunca Nehirlerinin Edirne ili sınırları içerisinde yer alan kısımlarında taşkın analizini yapmış, taşkın sularının 1955-1975 yılları arasında seddelenmiş arazide kalan yerleșim yerleri ve sosyal yaşam alanlarının taşkından etkilendiğini ortaya koymuştur.

Oğraş (2018), HEC-RAS paket programını kullanarak Dicle Nehri'nin Diyarbakır'dan Silvan'a olan karayolu köprüsü ile tarihi On Gözlü Köprü arasında kalan kısmın taşkın analizini yapmıştır. Yapılan taşkın analizi sonucu: On Gözlü Köprü ve Sadi Köprüsü hidrolik açıdan açıklıkların yetersiz olduğunu, UNESCO tarafından Dünya Kültür Mirası Listesine alınmış olan Hevsel Bahçeleri, Dicle Üniversitesinin Kaptajı, Arıtma Tesisleri, Taşıt İşletme Şubesi, Diyarbakır Orman Bölge Müdürlüğüne bağlı fidanlık saha, Balıkçılık ve Meyvecilik geliştirme projesi kapsamında işletmedeki tesis ve Üniversite Köprüsü membasında bulunan yerleşim yerlerinin taşkından etkilendiğini ortaya koymuştur.

Akkoç (2019); HEC-RAS paket programını kullanarak Kars Çayı'nın Kars merkezden geçen kısmın taşkın analizini yapmış, taşkın analizi sonucunda Kars merkezinin taşkından etkilendiğini ortaya koymuştur.

Yıldırım (2020); HEC-RAS paket programını kullanarak Sakarya ili Geyve ilçesi Karaçay Deresi'nin taşkın analizini yapmış, taşkın analizi sonucunda taşkın yayılım haritalarını oluşturmuş ve Geyve ilçe merkezinin ve verimli tarım arazilerinin taşkından etkilendiğini ortaya koymuştur.

Demir (2020), Uzaktan alglama ile Sentinel-2 uydu görüntüsünün kontrollü sınıflandırmasını yaparak pürüzlülük katsayıları için arazi kullanım haritasını oluşturmuştur. $\mathrm{Bu}$ oluşturulan harita taşkın analiz programlarında kullanılmıştır. HECRAS ve FLO 2D programlarını kullanarak Merte Irmağı Havzasının Samsun ili kent sınırları ile kesiştiği kısmın taşkın analizini yapmış, Taşkın analizi sonucu taşkın tehlike ve taşkın risk haritalarını oluşturmuştur.

Taşkın hidrolik modellemelerinde; bir boyutlu modelleme kolay ve basit olmasına karşın, suyun dere yatağından taşarak geniş alanlara yayılması durumunda; geniş yayılım alanlarındaki davranışını (taşkın dalgasının, yatay eksendeki davranışının modellenememesi, topoğrafya ve en kesitlerin modele tam olarak yansıtılamaması gibi) gerçekçi bir biçimde yansıtmamaktadır. $\mathrm{Bu}$ eksikliklerin giderilebilmesi için 2 boyutlu modelleme tercih edilmektedir. $\mathrm{Bu}$ modelleme karmaşık ve zahmetlidir. Dolayısıyla taşkını daha iyi modellemek için her iki modelleme birlikte kullanılarak bütünleşik hidrolik modelleme adı verilen hibrit modelleme kullanılmaktadır (DSİ, 2019).

HEC-RAS programı ABD ordusu tarafindan geliştirilmiş olup 1995 yılından bu yana ücretsiz olarak tüm dünya ile paylaşılmaktadır. Program 
doğal derelerde, kontrol tesisi yapılmış derelerde, enine savak yapılarında, dik savak yapılarında, baraj yıkılmalarında, sel kapanlarında, menfez, küprü vb. yapılarda hidrolik modelleme yapabilmektedir. Birçok nehri birbirine bağlantılı bir ağ şeklinde analiz edebilmektedir. Kararlı ve kararsız akımda çalışabilmektedir. Yine bu program 1 boyutlu ve 2 boyutlu hidrolik modellemeleri ayrı ayrı yapabildiği gibi entegreli de yapabilmektedir. Programın 5.3 sürümünden önceki versiyonlarında haritalardan kesit oluşturma kısmı 2. bir yazılımda yapılıp HECRAS programına aktarılıyordu, 5.3 versiyonu ile kesit alma işlemlerini kendi içerisinde RAS Mapper menüsünde yapmaya başladı, 2. bir yazılıma olan gereksinimi ortadan kaldırdı. Henüz 3 boyutlu hidrolik modelleme yapamamaktadır. Bunların yanı sira sediment ve su kalitesi analizleri de yapmaktadır. Yapılan her türlü analizlerin sonuçlarını tablosal ve harita ekranında grafiksel olarak verebilmektedir. En son sürümü HEC-RAS 6.0 versiyonudur. $\mathrm{Bu}$ sürüm ile gelen önemli özelliklerden biri de taşkın yayılım, hız, derinlik ve su yüzü profilini kendi içerisinde mevcut olan 3 boyutlu harita ekranında 3 boyutlu olarak gösterebilmektedir. Program DSİ, SYGM vb. kurum ve kuruluşlar tarafindan aktif olarak kullanılmaktadır.

$\mathrm{Bu}$ bağlamda yapılan bu çalışmada da uzaktan algılama ile 2020 yılına ait Sentinel-2 uydu görüntüsü kullanılarak kontrollü sinıflandırma yapılmıştır. Yapılan kontrollü sınıflandırma ile yerleşim yerleri, tarım arazileri ve ağaçlık alanlar belirlenmiștir. Bu kontrollü sınıflandırması yapılmış uydu görüntüleri sürtünme katsayılarını belirlemede ve taşkının etkilediği alanın türü ve miktarının belirlenmesinde kullanılmıștır. HEC-RAS programıla Çakmak Deresi üzerindeki menfez yapılarının sebep olduğu kesit değişimlerinin ve mevcut kesit değişimlerinin akıma olan etkisini belirlemekle birlikte oluşabilecek taşkının güzergâh üzerinde yer alan yerleşim yerlerine, tarım arazilerine ve ağaçlık alanlara olası etkisi tespit edilmeye çalışılmıştır.

\section{YÖNTEM}

Çalışma alanı Diyarbakır iline $32 \mathrm{~km}$ mesafede olan Çınar ilçe merkezindeki Çakmak Deresi'dir. Çakmak Deresi 21 no'lu Fırat-Dicle havzasının alt havzası olan Dicle havzasında yer almaktadır. Çakmak Deresi Çınar'ın Ağaçsever Mahallesi'nde doğar, Çınar merkezinden geçer ve Çınar'ın Başaklı Mahallesi'nde Dicle Nehri'ne boşalır. Çalışma alanı, Çakmak Deresi'nin Çınar merkezinde kalan 1600 m'lik kısmını kapsamaktadır. Yaklaşık rakımı 655 m olan Çakmak Deresi güneyden kuzeye doğru akmaktadır ve geçmişte birçok mesken ve tarım arazisi, taşkından kaynaklanan hasarlara maruz kalmıştır. Bu kısımda yerleşim yerleri mesire alanları ve tarım arazileri yer almaktadır. Çakmak Deresi'nin bu kesimde ortalama eğimi \%1'dir. Çınar'ın Türkiye'deki konumu Şekil 1'de ve Çınar merkezinin Sentinal-2 uydu görüntüsü Şekil 2'de verilmiştir.

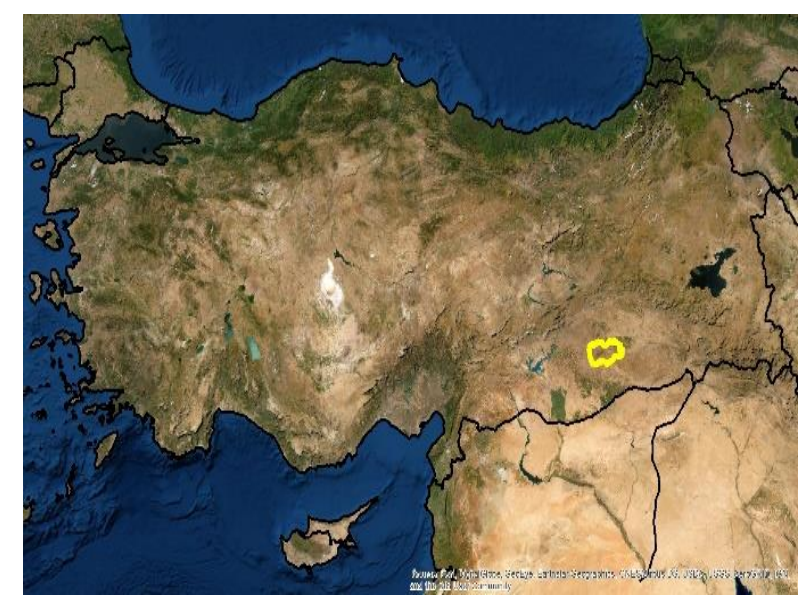

Şekil 1. Çalışma alanının (Çınar ilçe merkezinin) Türkiye haritasındaki konumu

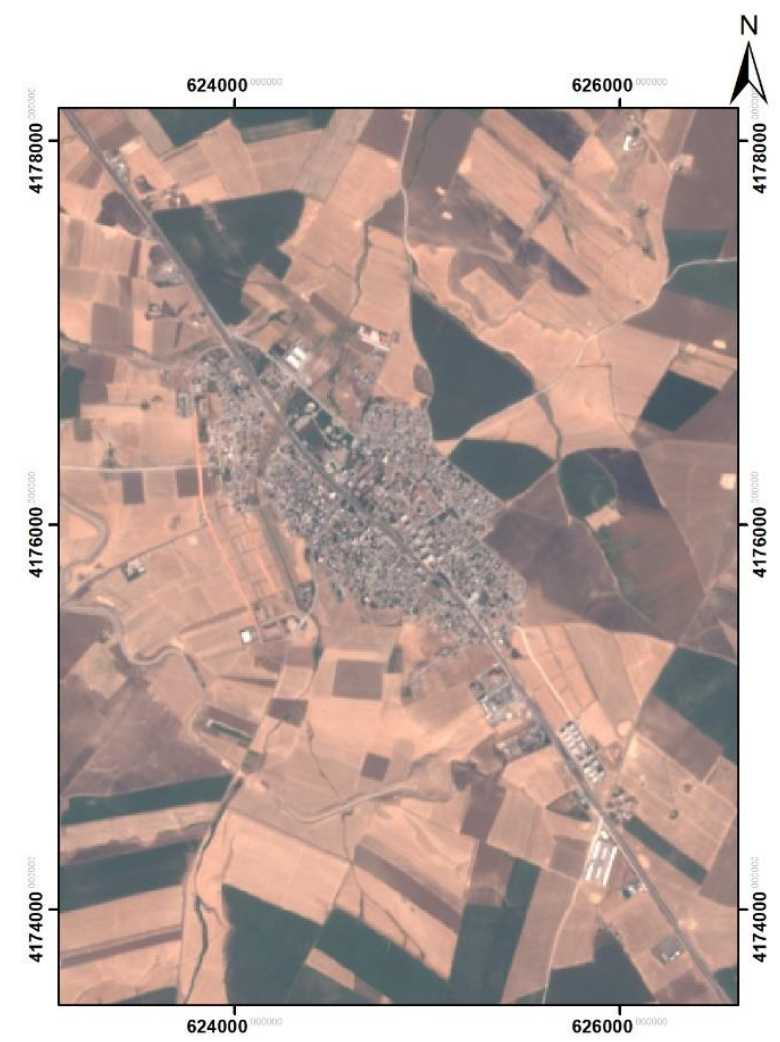

Şekil 2. Çalışma alanının (Çınar ilçe merkezinin) 2020 Sentinel-2 uydusunun doğal renk görüntüsü

Çalışma alanının 1/1000 ölçekli hâlihazır haritası, dere üzerindeki 5 adet menfezin röleveleri ve Q500 debisi (hidrografı) elde edilmiştir.

DSİ'den alınan Çakmak Deresi'nin debisi, çalışma güzergâhının mansabı referans alınarak DSİ sentetik metot yöntemine göre hesaplanmış olup, yağış alanı $124.1 \mathrm{~km}^{2}$ ve 500 yıllık tekerrürlü pik debisi Q500=149 $\mathrm{m}^{3} / \mathrm{s}^{\prime}$ dir. Zamana bağlı debi değişim hidrografı Şekil 3'te verildiği gibidir. 


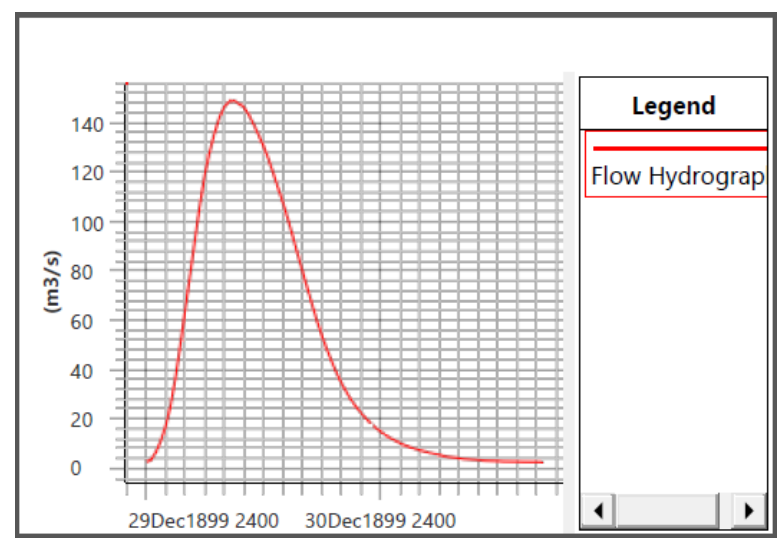

Şekil 3. Giriş hidrografı

Çakmak deresinin pürüzlülük n katsayısı dere yatağ 1 için DSİ taşkın ihtisas komisyonunca geliştirilen "Modifiye Cowan Metodu"na ait pürüzlülük tablosuna göre belirlenmiştir (DSİ, 2016).

Tablo 1. DSİ taşkın ihtisas komisyonunca geliştirilen "Modifiye Cowan Metodu"na ait pürüzlülük tablosu (DSİ, 2016)

\begin{tabular}{|c|c|c|c|c|c|}
\hline \multirow{9}{*}{$\begin{array}{l}\text { Yataktaki } \\
\text { malzeme } \\
\text { cinsi }\end{array}$} & Beton & \multirow{9}{*}{$\begin{array}{l}\text { Medyan dane çapı } \\
(\mathrm{mm})\end{array}$} & -- & \multirow{9}{*}{$\mathbf{n}_{\mathbf{b}}$} & $0.012-0.018$ \\
\hline & Kaya & & -- & & -- \\
\hline & Sert toprak & & -- & & $0.025-0.032$ \\
\hline & İri kum & & $1-2$ & & $0.026-0.035$ \\
\hline & İnce çakıl & & -- & & -- \\
\hline & Çakıl & & $2-64$ & & $0.028-0.035$ \\
\hline & İri çakıl & & -- & & -- \\
\hline & İri taş & & $64-256$ & & $0.030-0.050$ \\
\hline & Yumru kaya & & $>256$ & & $0.040-0.070$ \\
\hline \multirow{7}{*}{$\begin{array}{l}\text { Kanal şev } \\
\text { durumu }\end{array}$} & Pürüzsüz & \multirow{2}{*}{\multicolumn{2}{|c|}{ Beton duvar }} & \multirow{7}{*}{$\mathbf{n}_{1}$} & 0.000 \\
\hline & & & & & 0.003 \\
\hline & Önemsiz & \multirow{2}{*}{\multicolumn{2}{|c|}{$\begin{array}{l}\text { Taş duvar } \\
\text { İstiflitas tabkimat }\end{array}$}} & & 0.005 \\
\hline & & & & & 0.008 \\
\hline & Orta & \multicolumn{2}{|c|}{ Ağaçsız kaya/toprak yamaç } & & 0.010 \\
\hline & & \multicolumn{2}{|c|}{ İstifsiz taş tahkimat } & & 0.015 \\
\hline & Şiddetli & Ağaçlı yamaç & & & 0.020 \\
\hline \multirow{3}{*}{$\begin{array}{l}\text { Kanal } \\
\text { kesit } \\
\text { değişimi }\end{array}$} & Așamalı & & & \multirow{3}{*}{$\mathbf{n}_{2}$} & 0.000 \\
\hline & Ara sıra değișen & & & & 0.005 \\
\hline & Sik değişen & & & & $0.010-0.015$ \\
\hline \multirow{4}{*}{$\begin{array}{l}\text { Kanaldaki } \\
\text { engeller } \\
\text { (birikinti, } \\
\text { tümsek, } \\
\text { düşü, } \\
\text { kaya, } \\
\text { köprü } \\
\text { ayağı) }\end{array}$} & İhmal edilebilir & \multirow{4}{*}{$\begin{array}{l}\text { Engel/kesit alanı } \\
\mathrm{x} 100\end{array}$} & $<\% 5$ & \multirow{4}{*}{$\mathbf{n}_{3}$} & 0.000 \\
\hline & Önemsiz & & $\% 5-15$ & & $0.010-0.015$ \\
\hline & Kayda değer & & $\begin{array}{l}15- \\
50 \\
\end{array}$ & & $0.020-0.030$ \\
\hline & Şiddetli & & $>\% 50$ & & $0.040-0.060$ \\
\hline \multirow{4}{*}{$\begin{array}{l}\text { Kanal } \\
\text { bitki } \\
\text { örtüsü }\end{array}$} & Düşük & & & \multirow{4}{*}{$\mathbf{n}_{4}$} & $0.005-0.010$ \\
\hline & Orta & & & & $0.010-0.025$ \\
\hline & Yüksek & & & & $0.025-0.050$ \\
\hline & Çok yüksek & & & & $0.050-0.100$ \\
\hline \multirow{3}{*}{$\begin{array}{l}\text { Kanal } \\
\text { kıvrımı }\end{array}$} & Önemsiz & Dere uzunluğu / & $1-1.2$ & \multirow{3}{*}{$\mathbf{m}$} & 1.000 \\
\hline & Kayda değer & kuş uçuşu & $1.2-1.5$ & & 1.150 \\
\hline & Siddetli & uzunluğu & $>1.5$ & & 1.300 \\
\hline
\end{tabular}

Pürüzlülük n katsayısını belirlemek için dere yatağının Şekil 4'teki resmi yorumlanmış olup Tablo 1'deki değerler ile eșleștirilmiștir. Dere tabanı beton kaplı olup yanları da kargir duvardan oluşmaktadır. Yataktaki malzeme cinsi beton kaplı olduğundan aralıktaki üst değer olan $n_{b}=0.018$ alınmıştır. Kanal şev durumu kargir duvar olduğundan $n_{1}=0.005$ alınmıştır. Kanal kesit değişimi aşamalı olduğundan $n_{2}=0.000$ alınmıștır. Kanaldaki engeller (Birikinti, Tümsek, Düşü, Kaya ve Köprü Ayağı) (Engel/Kesit alanı)x100<\%5 olduğundan $n_{3}=0.000$ alınmıștır. Kanal bitki örtüsü olmadığından $n_{4}=0.000$ alınmıștır. Kanal kıvrımı dere uzunluğu/kuş uçuşu uzunluk $=1600 / 1380=1.16$ bu değer $1-1.2$ aralığında olduğu için önemsiz sayıldığından $m=1$ alınmıștır. Alınan değerler formül (1)'de yerine yerleştirilince pürüzlülük $n$ değeri Tablo 2'deki gibi 0.023 olarak bulunmuştur.

$n=m *\left(n_{b}+n_{1}+n_{2}+n_{3}+n_{4}\right)$

Tablo 2. Çakmak deresi pürüzlülük $n$ değeri

\begin{tabular}{ll}
\hline Katsayı & Değer \\
\hline$n_{b}$ & 0.018 \\
$n_{1}$ & 0.005 \\
$n_{2}$ & 0.000 \\
$n_{3}$ & 0.000 \\
$n_{4}$ & 0.000 \\
$m$ & 1.000 \\
$n=m *\left(n_{b}+n_{1}+n_{2}+n_{3}+n_{4}\right)$ & 0.023 \\
\hline
\end{tabular}

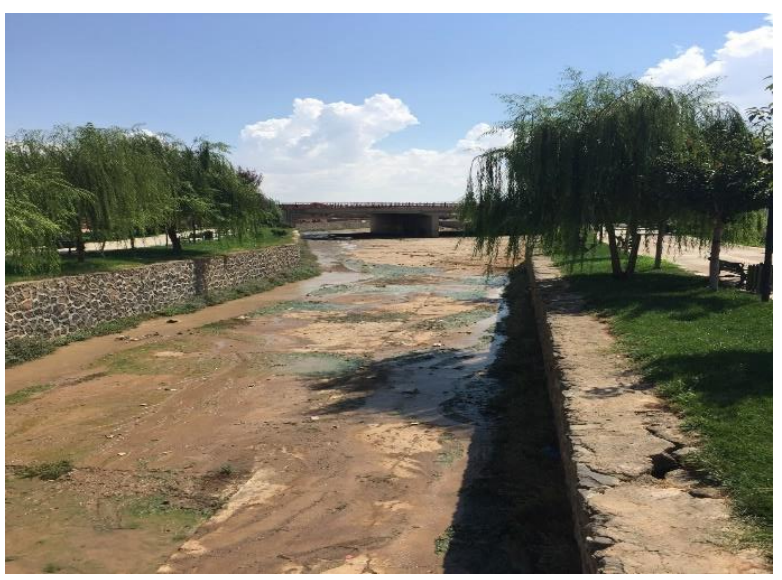

Şekil 4. Çakmak deresinin fiziki durumu

Dere yatağı dışındaki taşkın alanlarının pürüzlülük n katsayıları uzaktan algılama ile Chow 1959'daki katsayılara göre pixel bazlı belirlenmiştir (Chow, 1959). Bu bağlamda taşkın alanlarının arazi kullanım durumu tarım arazileri, ağaçlık alanlar ve yerleşim yerleri olarak 3 sınıfta ele alınmıştır. $\mathrm{Bu}$ çalışma için öncelikle Çakmak deresinin 19.09.2020 tarihine ait ücretsiz Tablo 3'teki band özelliklerine sahip Sentinel-2 uydu görüntüsü internetten indirilmiştir (URL-1).

Tablo 3. Sentinel-2 uydu görüntülerinin band bilgileri (URL-2)

\begin{tabular}{ccrc}
\hline Band & Açıklama & $\begin{array}{c}\text { Dalga } \\
\text { Boyu } \\
(\boldsymbol{\mu} \mathbf{m})\end{array}$ & $\begin{array}{c}\text { Mekânsal } \\
\text { Cözünürlük } \\
(\mathbf{m})\end{array}$ \\
\hline \multirow{2}{*}{1} & Kiyllar ve aerosol & $\begin{array}{r}0.433 \\
-0.453\end{array}$ & 60 \\
& & 0.458 & 10 \\
2 & Mavi (B) & -0.523 & \\
& & 0.543 & 10 \\
3 & Yeşil (G) & -0.578 & \\
\multirow{2}{*}{4} & & 0.650 & 10 \\
& Kirmızı (R) & -0.680 & \\
\multirow{2}{*}{5} & Bitki örtüsü & 0.698 & 20 \\
& kirmızı kenar & -0.713 & 20 \\
\hline
\end{tabular}


Tablo 3'ün devamı

\begin{tabular}{|c|c|c|c|}
\hline 6 & $\begin{array}{l}\text { Bitki örtüsü } \\
\text { kırmızı kenar }\end{array}$ & $\begin{array}{r}0.733 \\
-0.748\end{array}$ & 20 \\
\hline 7 & $\begin{array}{l}\text { Bitki örtüsü } \\
\text { kırmızı kenar }\end{array}$ & $\begin{array}{r}0.773 \\
-0.793\end{array}$ & 20 \\
\hline 8 & Yakın kızıl ötesi & $\begin{array}{r}0.785 \\
-0.900\end{array}$ & 10 \\
\hline $8 A$ & $\begin{array}{l}\text { Daraltılmış Yakın } \\
\text { kızıl ötesi }\end{array}$ & $\begin{array}{r}0.855 \\
-0.875\end{array}$ & 20 \\
\hline 9 & Su buharı & $\begin{array}{r}0.935 \\
-0.955\end{array}$ & 60 \\
\hline 10 & $\begin{array}{l}\text { Kısa dalga kızıl } \\
\text { ötesi-sirüs }\end{array}$ & $\begin{array}{r}1.365 \\
-1.385\end{array}$ & 60 \\
\hline 11 & $\begin{array}{l}\text { Kısa dalga kızıl } \\
\text { ötesi-1 }\end{array}$ & $\begin{array}{r}1.565 \\
-1.655\end{array}$ & 20 \\
\hline 12 & $\begin{array}{l}\text { Kısa dalga kızıl } \\
\text { ötesi- } 2\end{array}$ & $\begin{array}{r}2.100 \\
-2.280\end{array}$ & 20 \\
\hline
\end{tabular}

İndirilen uydu görüntüsünün bantları QGIS programında açılmıştır. SCP (Semi-Automatic Classification Plugin) eklentisinde açlan bantların çalışma alanına denk gelen kısımları kesilmiștir. Kesilmiş bantlara atmosferik düzeltme yapılmıştır.

Kontrollü sınıflandırma için bantlar üzerinde 3 ana sınıf olmak üzere 17 tane yerleşim alanı alt sınıfı, 15 tane tarım arazisi alt sınıfı ve 4 tane ağaçlık alanı alt sınıfı olmak üzere toplamda 36 eğitim sınıfı seçilmiştir. Daha sonra maksimum olasllık, minimum mesafe ve Spektral açı haritası algoritmalarını göre 3 ayrı yöntemle kontrollü sınıflandırma yapılmıştır.

Kontrollü sinıflandırmada kullanılan algoritmalardan en iyi sonucu vereni tespit etmek için doğruluk analizi yapılmıştır. Doğruluk analizi için 3 ana sınıf olmak üzere 9 tane yerleşim alanı alt sınıfı, 6 tane tarım arazisi alt sınıfı ve 5 tane ağaçlık alanı alt sınıfı olmak üzere toplamda 20 adet test sınıfı seçilmiştir. Kontrollü sinıflandırma sonucu oluşan sınıflandırma verileri ile test verileri kıyaslanmış olup, her üç algoritma sonucu oluşan kontrollü sınıflandırma verilerinin doğruluk analizi yapılmıştır. Tablo 4'te verilen değerler elde edilmiş olup en iyi sonucu, Spektral açı haritası algoritmasının verdiği anlaşılmıştır.

Tablo 4. Doğruluk analizi sonuçları

\begin{tabular}{ccc}
\hline Algoritmalar & $\begin{array}{c}\text { Genel Doğruluğu } \\
\text { [\%] }\end{array}$ & Kappa Değeri \\
\hline $\begin{array}{c}\text { Maksimum } \\
\text { olasillk } \\
\text { Minimum } \\
\text { mesafe }\end{array}$ & 73.7404 & 0.556 \\
$\begin{array}{c}\text { Spektral açı } \\
\text { haritası }\end{array}$ & 82.5978 & 0.6805 \\
\hline
\end{tabular}

"Kappa değerinin \%75 ve üzeri olması durumunda sınıflandırmanın çok iyi olduğu, \%40\%75 arası olması durumunda sinıflandırmanın ortaiyi olduğu, \%40'ın altında olması durumunda ise sınıflandırmaların zayıf olarak değerlendirilmesi yapılmaktadır." (Demir, 2020, s.127).
Dere yatağı dışındaki taşkın alanlarının pürüzlülük n katsayıları Chow 1959'daki katsayılara göre pixel bazlı belirlenmiştir (Chow, 1959). Spektral açı haritası algoritmasının kontrollü sınıflandırılması sonucu Şekil 5'teki harita elde edilmiştir. $\mathrm{Bu}$ haritada yerleşim yerleri olarak atanan kırmızı pixellerde $n=0.060$, tarım arazileri olarak atanan turuncu pixellerde $n=0.5$ ve ağaçlık alanlar olarak atanan yeşil pixellerde $n=0.8$ alınmıştır.

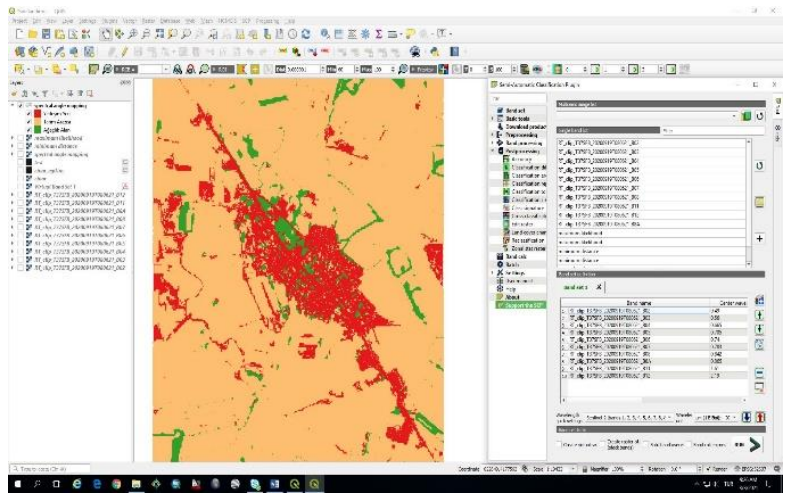

Şekil 5. Spektral açı haritası algoritması ile kontrollü sinıflandırma

Dere yataklarında daralma ve genişlemelerden kaynaklı enerji kayıpları söz konusudur (HEC-RAS, 2020). Çalışma sahamızdaki derenin daralma ve genişlemesi menfez geçişlerinden kaynaklı olup Tablo 5'teki gibi aşamalıdır.

Tablo 5. Dere yataklarındaki daralma ve genişleme katsayıları (HEC-RAS, 2020)

\begin{tabular}{lccc}
\hline \multicolumn{2}{l}{ Güzergâh Durumu } & Daralma & Genişleme \\
\hline $\begin{array}{l}\text { Güzergâhta } \\
\text { yok }\end{array}$ & geçiş & 0.0 & 0.0 \\
$\begin{array}{l}\text { Güzergâhta } \\
\text { geçiş }\end{array}$ & aşamalı & 0.1 & 0.3 \\
$\begin{array}{l}\text { Standart } \\
\text { geçişi }\end{array}$ & köprü & 0.3 & 0.5 \\
Ani dik geçiş & 0.6 & 0.8 \\
\hline
\end{tabular}

HEC-RAS programında taşkın analizi yapmak için ilk önce çalışma alanının hâlihazır haritası (raster verisi) ile 2 boyutlu taşkın alanlarının sürtünme katsayısı için uzaktan algılama ile üretilen Kontrollü sınıflandırma yapılmış uydu görüntüsü (raster verisi) HEC-RAS programına aktarılmıştır. Çakmak Deresi'nin Çınar merkezinden geçen 1600 m'lik kısmında dere yatağı ortasından geçecek şekilde membadan mansaba doğru $1600 \mathrm{~m}$ uzunluğunda güzergâh çizilmiştir. Derenin üst şevlerinden geçecek şekilde membadan mansaba doğru önce sağ sahil sonra sol sahil çizgileri çizilmiştir. Sağ ve sol şev üst çizgilerini çizme nedeni kanal içinin ve kanal dışının pürüzlülük katsayıları için alanları ayırmaktır. Hidrolik hesaptaki daralma ve genişlemelerden kaynaklı enerji kayıp 
hesaplarının yapılması için güzergâh ekseni, sağ tașkın alanı ve sol tașkın alanlarının kesitler arasındaki mesafesinin belirlenmesi için çizilmiștir. 1 boyutlu hidrolik hesaplar için $20 \mathrm{~m}$ aralıklar ile sol sahilden să̆ sahile olacak şekilde en kesitler çizilmiştir. Suyun kanalın dışına taşan sağ ve sol sahildeki alanların 2 boyutlu hidrolik hesapları için sağ ve sol sahilde 2 boyutlu taşkın alanları çizilmiştir. 1 boyutlu ve 2 boyutlu hibrit hidrolik modelin çalışması için dere yatağı şev üstü ile 2 boyutlu taşkın alanlarını birbirine bağlayan yanal savaklar çizilmiştir. Dere yatakları ve taşkın alanları için elde edilen sürtünme katsayıları girilmiştir. 5 adet menfezin röleveleri girilmiştir. Dere yatağının şev başları sedde olarak tanımlanmıştır. Memba sınır koşulu olarak debi (hidrograf) mansap sınır koşulu olarakta derenin ortalama eğimi olan \%1 eğim girilmiștir. Ayarlar ve tolerans değerleri girilip boyutlu ve 2 boyutlu hibrit hidrolik modelleme çalıştırlıp sonuçlar elde edilmiştir.

Kontrollü sınıflandırma sonucu proje sahasının yerleşim yerleri, tarım arazileri ve ağaçlık alanlar belirlenmiștir. Hidrolik model sonucu olușan taşkın yayılımı ile uzaktan algılama ile üretilen arazi kullanım durumu çakıștırılıp; taşkından etkilenen yerleșim alanlarının, tarım arazilerinin ve ağaçlık alanların yüz ölçümleri belirlenmiştir.

\section{BULGULAR}

Q500 taşkın tekerrür debi değeri kullanılarak Çakmak Deresi için HEC-RAS programıyla 1 boyutlu ve 2 boyutlu hibrit hidrolik modelleme yapılmıștır. Yapılan modellemenin taşkın yayılım alanını ve yapılarla olan ilişkisini gösteren 3 boyutlu harita görseli Şekil 6'da verilmiştir.

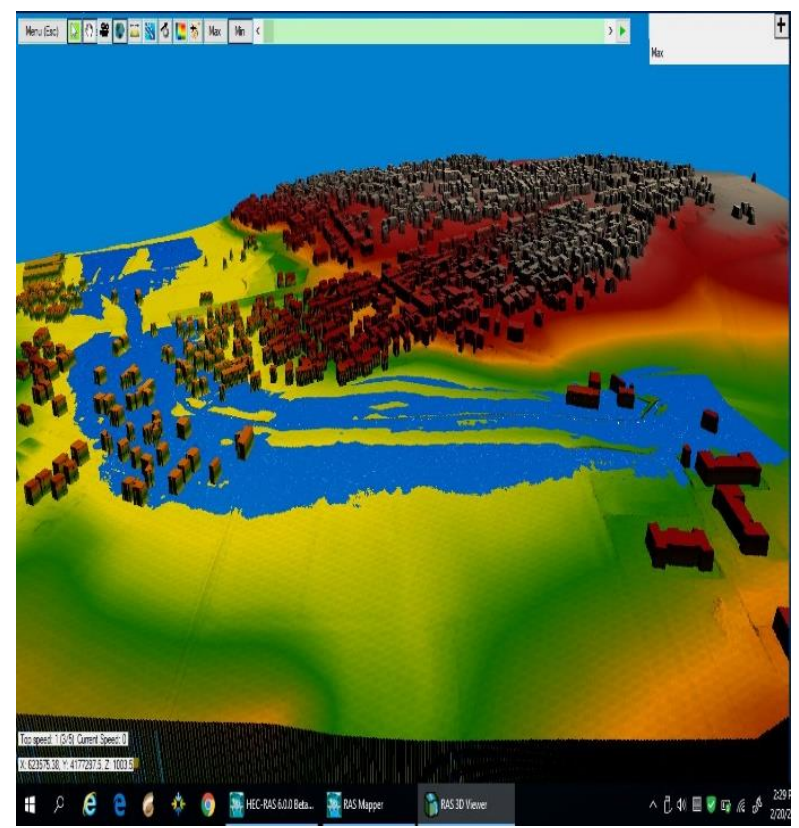

Şekil 6. Maksimum debideki taşkın yayılımının 3 boyutlu harita görseli

HEC-RAS programı hidrolik model üzerinde kolayca değişiklikler yapılmasına olanak sağlamaktadır. $\mathrm{Bu}$ program ile yapılan hidrolik modelleme sonucunda noktalar arasındaki kritik hız farkları ya da enerji kayıpları varsa, bunlar raporlanmaktadır. Rapordaki sonuçlar incelenip değerlendirilerek ilave en kesitlere ihtiyaç duyulan bölgeler belirlenebilmektedir. Modelleme sonucunda taşkın yayılım alanı, su derinliği, su yüzü profili ve su hız değerleri elde edilmiştir. Menfezlerden kaynaklı kesitlerde oluşan daralmaların neden olduğu su kabarmaları sonucu suyun kesitten taştığı yerlerde menfez ebatlarının arttırılması gerektiği tespit edilmiştir. Mevcut taşkın kontrol tesisinin yer yer kapasitesinin yetmediği ve taşkının olduğu anlaşılmıştır. Ayrıca HEC-RAS programının RAS Mapper ara yüzü ile sonuçların görsel haritaları elde edilmiştir.

Yapılan taşkın modellemesi sonucu Şekil 7'de de görüldüğü üzere yerleşim yerlerinin olduğu bölgede su maksimum 3.60 m'ye kadar yükselmiştir.

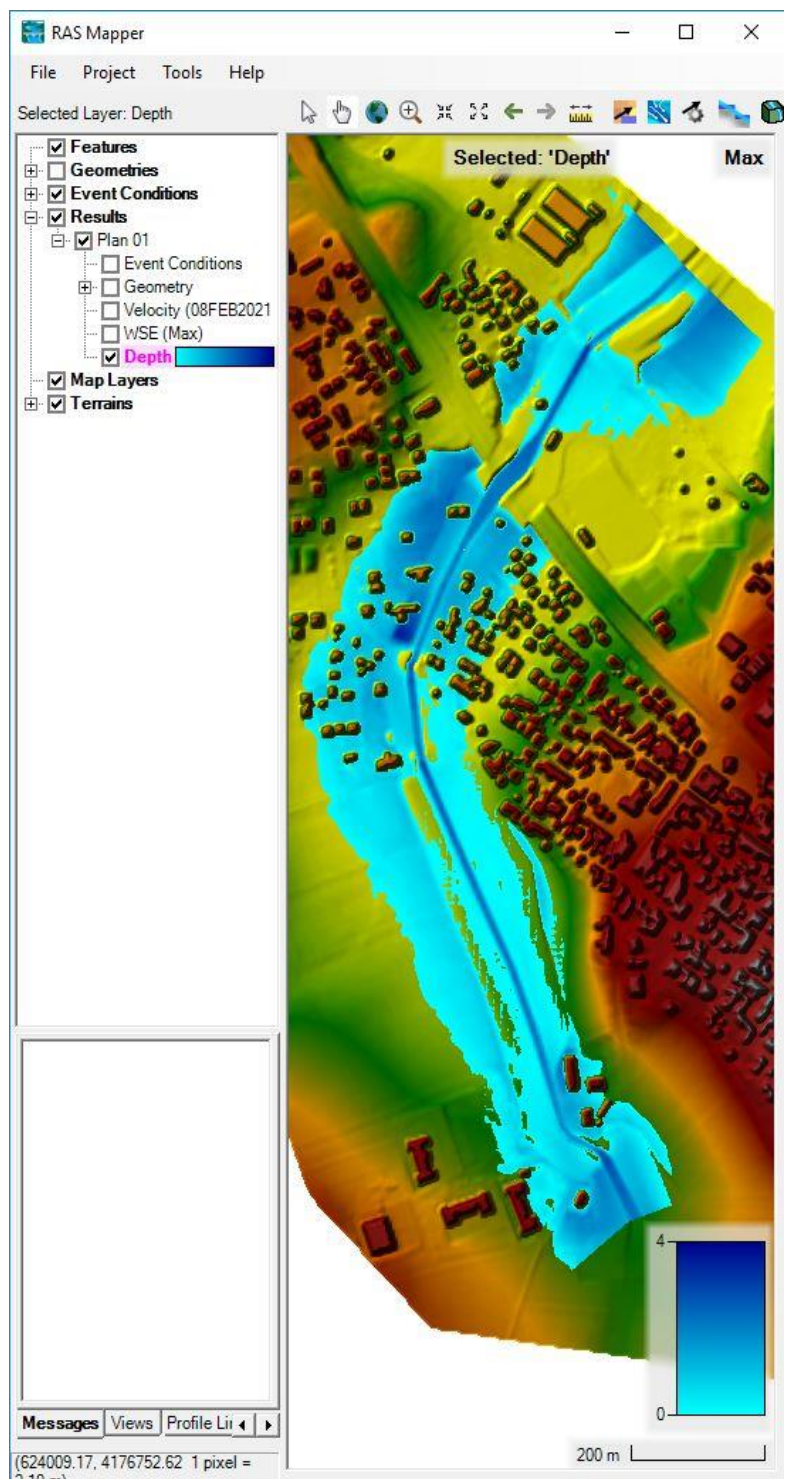

Şekil 7. Maksimum debideki taşkın su derinliği haritası

Su hızı Şekil 8'de de görüldüğü üzere dere yatağı içerisinde maksimum 7.19 m'ye kadar ulaşmıştır. 


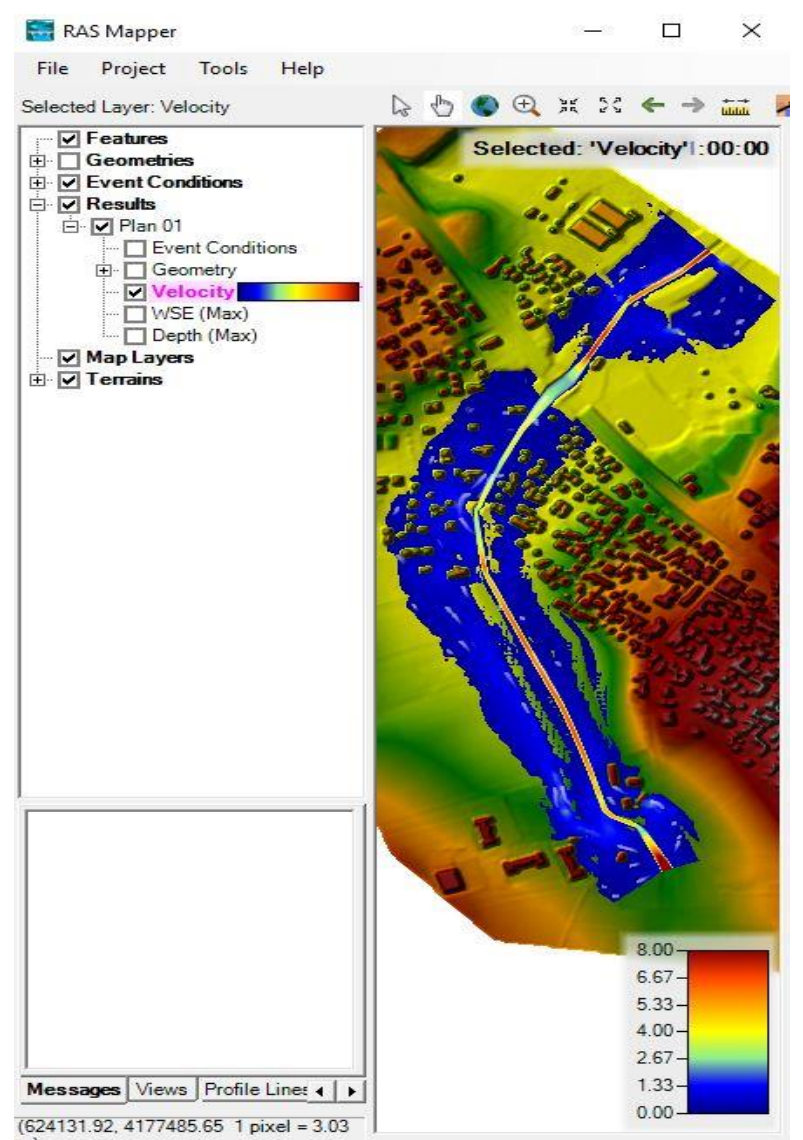

Şekil 8. Maksimum debideki taşkın su hızı haritası

Su yüzeyinin üst kotları Şekil 9'da da görüldüğü üzere çalışma güzergâhının başladığı noktada 661.24 m'de başlayıp çalışma güzergâhının son bulduğu noktada 648.72 m'ye düşmüştür.

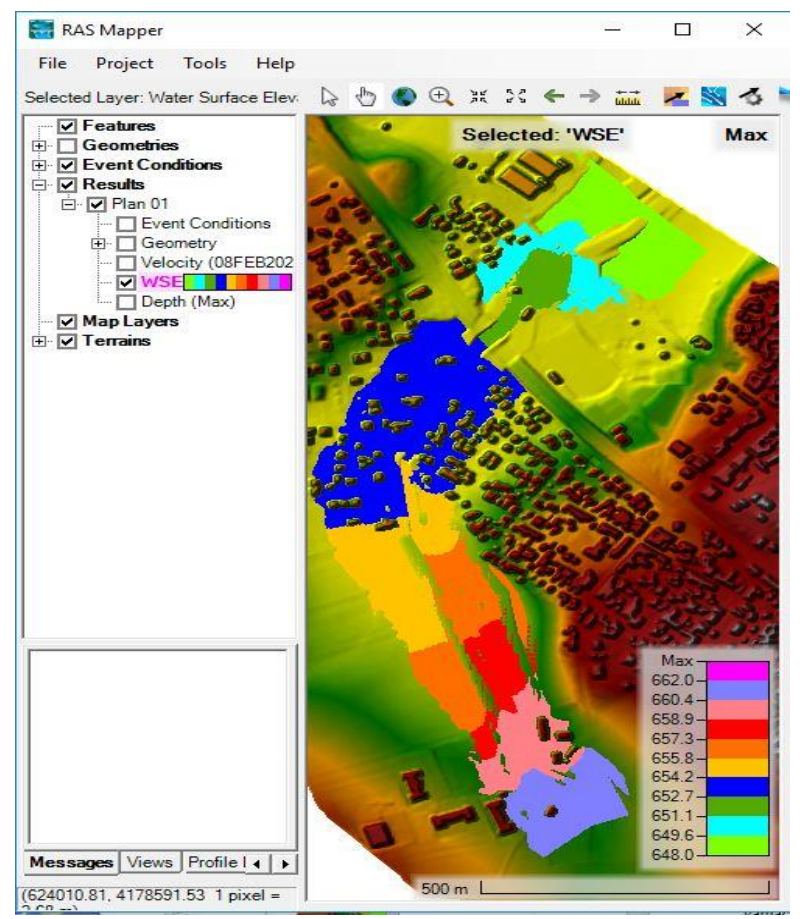

Şekil 9. Maksimum debideki taşkın su yüzü yükseklik profili haritası

QGIS programında Sentinel 2 uydu görüntüsünün kontrollü sınıflandırması Şekil 10'da görüldüğü üzere yapılmıştır. Yapılan doğruluk analizi sonucunda en iyi sonucu spektral açı haritası algoritmasının verdiği anlaşılmıştır. Taşkın yayılım haritası ile kontrollü sınıflandırma sonucu üretilen arazi durum haritası çakıştırılmıştır. $135985 \mathrm{~m}^{2}$ yerleşim yeri, $126326 \mathrm{~m}^{2}$ tarım arazisi ve $51548 \mathrm{~m}^{2}$ ağaçlık alan taşkından etkilendiği tespit edilmiştir.

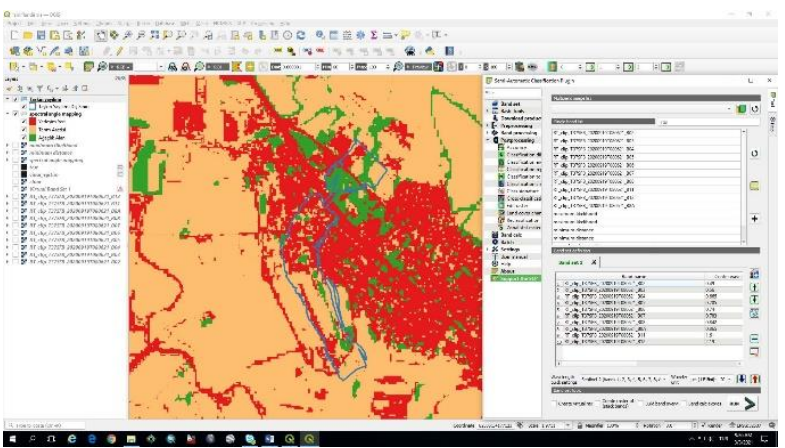

Şekil 10. Uzaktan algılama kontrollü sınıflandırma haritası

\section{SONUÇLAR}

Çakmak Deresi yatağının etrafında eski yapılar olduğundan imar planı yapılırken bazı kısımlar yerleşime açılmış. Dere yatağının yanına alçak kotlara yapılar yapılmış. 2006 yılında yağmurun şiddetli ve uzun süre yağması sonucu DiyarbakırMardin kara yolu altında bulunan menfezin ebatları hidrolik açıdan yetersiz olduğundan; su, menfez arkasında şişip menfezin üstünü aşıp kara yolu üzerinden akmaya başlamış. Suya kapılan bir minibüsün devrilmesi sonucunda 3 vatandaş hayatını kaybetmiş ve birçok ev, su ve çamur altında kalmış. KGM tarafından 2006 yılında DiyarbakırMardin karayoluna hidrolik kapasiteyi kurtaracak ebatlarda 2 gözlü menfez yapılmış. DSİ Genel Müdürlüğü tarafından 2008 yllında Çakmak Deresi'nde Diyarbakır-Mardin kara yolu altında bulunan menfezin taban kotu referans alınarak taşkın kontrol tesisi yapılmış. Yapılan taşkın kontrol tesisinin tabanı beton kaplı olup duvarları kâgir duvardan oluşmakta. Taşkın kontrol tesisi yamaçlardan gelecek suyu içine mansaplayacak şekilde gömülü olarak, Diyarbakır-Mardin kara yolu menfezinin taban kotundan ve teknik açıdan ötürü inşa edilememiş. Taşkın kontrol tesisinin duvar üst kotu etrafindaki arazilerden yer yer $2 \mathrm{~m}$ kadar yüksekte kalıp duvarların etrafında alçak kotlarda evler mevcuttur. Yağmurun şiddetli yağdığı dönemlerde yamaçlardan gelen sular taşkın kontrol tesisinin duvarları etraftaki arazilerden yüksekte olduğundan kanal içine mansaplanamamakta ve bu nedenle evlerin etrafinda su birikintileri olușmakta. Vatandaşlar yamaçlardan gelen suyu taşkın kontrol tesisinin içine mansaplamak için yer yer taşkın kontrol tesisinin duvarlarını yıkmışlar. Yüksek yağış dönemlerinde kanal içerisinde yağmur suyunun yükselmesi sonucu yağmur suyu duvarın yıkıldı̆̆ı yerlerde dışarıya taşarak evlerin etrafında birikmekte. Bu sorunun giderilmesi için taşkın 
kontrol tesisinin paralelinde bulunan yamaçlardan gelen yüzeysel suların yağmur suyu hattına alınması gerekmekte. Taşkın kontrol tesisinin yıkılan kısımlarının da onarılarak, kanalda yağmur suyu yükseldiğinde dışarıya taşmasını engelleyerek etraftaki evlerin zarar görmesi engellenmeli. Mevcut sslah tesisinin 1600 m'lik kısmında 1 boyutlu ve 2 boyutlu entegreli hidrolik modelleme yapılmış. $\mathrm{Bu}$ güzergah üzerinde toplamda bulunan 5 adet menfez de hidrolik modele dahil edilmiş. Yapılan hidrolik model sonucunda mevcut taşkın kontrol tesisi ve 4 adet menfez Q500=148.9 m3/s debiyi geçirememekte olup taşkın suları kanaldan taşarak etraftaki yerleşim yerlerine, tarım arazilerine, parklara, bahçelere vb. yerlere zarar vermekte. Taşkın kontrol tesisi yalnızca Diyarbakır-Mardin kara yolunda taşmamakta.

Taşkın kontrol tesisinin kapasitesinin yetersiz olmasının nedeni tasarlandığı dönemdeki yağış verilerinden kaynaklı debinin düşük olması ve manning katsayısı için referans alınan kriterlerin farklı olmasından kaynaklı manning katsayısının düşük olduğu düşünülmekte. Bu çalışmada taşkın analizi yapılırken kullanılan debi ve manning katsayıları DSİ tarafından 2008 yılında yapılan taşkın kontrol tesisinin debi verisi ve sürtünme katsayısından daha büyük çıktığından yapılan taşkın analizi sonucunda mevcut taşkın kontrol tesisinin kapasitesinin yetersiz olduğu anlaşılmıştır.

Yukarıda belirtilen nedenlerden ötürü dere yatağının etrafında yağmur suyu hattı yapılmalı. Taşkın kontrol tesis duvarının yıkıldığı yerler onarılmalı. Taşkın kontrol tesisinin duvarları güncel debi ve manning katsayısını kurtaracak şekilde yükseltilmeli. Diyarbakır-Mardin kara yolu altındaki menfez hariç diğer 4 menfezin ebatları hidrolik kapasiteyi kurtaracak şekilde büyütülmeli. Taşkın kontrol tesisinde manning katsayısının artışına neden olan rüsubat ve bitki yeșermelerinin düzenli olarak temizlenmesi gerekmekte. Yukarıda belirtilen problemlerin giderilmesi durumunda, taşkın kontrol tesisi Q 500 debisini güvenli olarak geçirecek olup etrafındaki yapıların zarar görmesi engellenmiş olacak.

\section{TEŞEKKÜR}

$\mathrm{Bu}$ çalışmada kullanılan harita ve hidrolojik verilerin temininde destek sağlayan Devlet Su İşleri Diyarbakır 10. Bölge Müdürlüğüne teșekkür ederim.

\section{KAYNAKÇA}

Akkaya, U. (2016). Meriç ve Tunca Nehirlerinin Edirne Şehir Merkezi Kısmında 2 Boyutlu Taşkın Modellemesi. Doktora Tezi, Sakarya Üniversitesi, Sakarya.

Akkoç, N. F. (2019). Aras Havzası Kars Çayı 1D ve 2D Taşkın Analizi. Yüksek Lisans Tezi, Gazi Üniversitesi, Ankara.

Bolat, S. (2019). Taşkın Modellemeleri İçin Farklı Uzaktan Algılama Görüntülerinden Elde Edilen
Pürüzlülük Haritalarının Karşılaştırılmasi. Yüksek Lisans Tezi, İstanbul Üniversitesi, İstanbul.

Chow, V. T. (1959). Open Channel Hydraulic. McGraw-Hill. 1- 728, New York.

Demir, V. (2020). Samsun Mert Havzasında Bir ve İki Boyutlu Modeller İle Taşkın Alanlarının Belirlenmesi. Doktora Tezi, Ondokuz Mayıs Üniversitesi, Samsun.

DSİ, (2016). Dere Yataklari İçin Pürüzlülük Katsayısı Belirleme Kılavuzu. Orman ve $\mathrm{Su}$ İşleri Bakanlığı, Devlet Su İşleri Genel Müdürlüğü, Ankara.

DSİ, (2019). Taşkın ve Rüsubat Kontrolü Planlama Raporlarının Hazırlanmasına Dair Kılavuz. Tarım ve Orman Bakanlı̆̆l, Devlet Su İşleri Genel Müdürlüğü, Ankara.

Efe, H. (2014). Batman Çayı'nın Taşkın Analizinin HEC-RAS Programıla Yapılması. Yüksek Lisans Tezi, Dicle Üniversitesi, Diyarbakır.

Ercan, B., Yağcl, A. E. \& Ünsal, M. (2019). Kahramanmaraş Domuz (Boğaz) Deresi Kuşaklama Kanalının HEC-RAS Modeli. Artvin Çoruh Üniversitesi Doğal Afetler Uygulama ve Araştırma Merkezi Doğal Afetler ve Çevre Dergisi, 2019, 5(1): 58-64.

HEC-RAS Version 6.0 Beta Hydraulic Reference Manual (2020).

Oğraş, S. (2018). Dicle Nehri'nin Taşkın Analizinin HEC-RAS Programıla Yapılması. Yüksek Lisans Tezi, Dicle Üniversitesi, Diyarbakır.

Özcan, O. (2008). Sakarya Nehri Alt Havzası'nın Taşkin Riski Analizinin Uzaktan Algılama ve CBS ile Belirlenmesi. Yüksek Lisans Tezi, İstanbul Teknik Üniversitesi, İstanbul.

Sargın, A. H. (2013). Coğrafi Bilgi Sistemleri İle Taşkın Riski Ön Değerlendirmesi. Ankara: CBS Şube Müdürlüğü.

Yıldırım, İ. (2020). Geyve Karaçay Deresi Taşkin Yayılım Haritalarının Oluşturulması. Yüksek Lisans Tezi, Sakarya Üniversitesi, Sakarya.

URL-1: https://earthexplorer.usgs.gov/ [Erişim Tarihi: 01.03.2021]

URL-2: https://blog.esriturkey.com.tr/2019/02/25 [Erişim tarihi: 01.03.202] 